\title{
Investigating Impacts of Therapeutic Strategies on Outcomes of Bactereamia Patients Captured by Varied Sepsis Definitions: Time for a Reappraisal of Sepsis-3 Criteria
}

Ching-Chi Lee ( $\nabla$ chichingbm85@gmail.com )

National Cheng Kung University Hospital https://orcid.org/0000-0002-4949-2742

Po-Lin Chen

National Cheng Kung University Hospital

Yi-Tzu Huang

Kaohsiung Medical University Hospital: Kaohsiung Medical University Chung Ho Memorial Hospital

Ming-Yuan Hong

National Cheng Kung University Hospital

Chih-Chia Hsieh

National Cheng Kung University Hospital

Chih-Hao Lin

National Cheng Kung University Hospital

Wen-Chien Ko

National Cheng Kung University Hospital

\section{Research}

Keywords: Sepsis-3 criteria, bactereamia patients, sepsis, therapeutic strategies

Posted Date: October 21st, 2020

DOI: https://doi.org/10.21203/rs.3.rs-93437/v1

License: (c) (i) This work is licensed under a Creative Commons Attribution 4.0 International License. Read Full License 


\section{Abstract}

Background: To early recognize septic patients, quick Sequential Organ Failure Assessment (qSOFA) was proposed by the Sepsis-3 guideline as the initial sepsis identification outside of intensive care units; however, the lack of consensus regarding the revised definition might impede efforts to treat septic patients. Our aim included validation of the new definition in patients with documented bactereamia, by means of the evaluation for the period of delayed treatment efforts and impacts of delayed treatment on prognosis of those categized by traditional or revised sepsis definitions.

Methods: In the multicentre cohort of adults with community-onset bactereamia in the emergency department, clinical information was retrospectively analyzed and causative isolates were prospectively stored for susceptibility testes. Using the Cox-regression model, effects of delayed administration of appropriate antimicrobials and adequate source control on 30-day crude mortality in varied SIRS and qSOFA categories were examined after respective adjustment for independent determinants of 30-day mortality.

Results: Of the total 3,898 adults, the time-to-appropriate antibiotic and time-to-source control in patients initially presented with SIRS scores of $\geq 2$ remained significant shorter than those with qSOFA scores of $\geq 2$. Effects of inappropriate EAT and inadequate source control on 30-day mortality were significant in patients who initially presented with SIRS scores of 2 (AOR, 3.06; $P<0.001$ and AOR, $1.49 ; P=0.04$ ) and 3-4 (AOR, 1.63 and AOR, 2.39; all $P<0.001$ ) but not in those with scores of 0-1 (AOR, 0.87; $P=0.88$ and AOR, 1.57; $P=0.79$ ). Notably, adverse impacts of inappropriate EAT and inadequate source control on 30 day mortality were significant in patients who initially experienced qSOFA scores of 0-1 (AOR, 2.05; $P=$ 0.004 and $A O R, 3.31 ; P=0.003)$, who were recognised as non-septic patients according to Sepsis-3 guidelines.

Conclusions: For patients with community-onset bacteraemia, definitions in the new Sepsis-3 guidelines might impede their treatment efforts in earlier stages and this delayed treatment consequently resulted in unfavourable outcomes. Accordingly, adopting a more restrictive sepsis definition that requires further progression along the sepsis pathway is necessary to avoid delayed interventions.

\section{Introduction}

Sepsis is a worldwide public health burden resulted in substantial mortality and morbidity that causes a considerable healthcare cost [1]. Early identification and treatment of sepsis have been demonstrated to result in favourable outcomes [2,3]. However, the identification of sepsis is difficult given its sometimes subtle clinical presentations in the real world [4]. Clinical risk assessments, such as the Sequential Organ Failure Assessment (SOFA), were developed to timely identify infected or septic patients at risk of mortality and serve as prompts to consider sepsis in unwell patients and rapidly facilitate appropriate treatment [5]. Therefore, in the setting of emergency departments or general hospital wards, the Sepsis-3 guidelines proposed the quick SOFA (qSOFA) as a replacement for the systemic inflammatory response 
syndrome (SIRS) criteria, which were deemed to have unfavourable specificity and sensitivity in septic patients [6]. Currently, although the clinical application of various sepsis definitions has been discussed for different patient populations [7-9], there is a lack of consensus regarding the representativeness of the Sepsis-3 criteria and whether they impede detection and treatment efforts $[10,11]$.

Bactereamia is the life-threatening condition linked to high mortality and morbidity and is generally acknowledged to be a serious type of systemic infections [12]. More importantly, the advantages of appropriate administration of empirical antimicrobials and source control, particularly in critically ill individuals, have been emphasised in cases of bloodstream infections [13-16]. It was understandable that we concerned the external validation of the Sepsis-3 guideline in bactereamia patients might lead to unfavorable patient prognoses, if the intervention was delayed in truly septic patients who were categorised as non-septic according to this new definition. Accordingly, focusing on adults with community-onset bactereamia, our aim included the companions for the period of delayed treatment efforts, in terms of appropriate antimicrobial therapy and adequate source control, and effects of delayed treatment efforts on the short-term prognoses between septic patients diagnosed by SIRS and SOFA scores.

\section{Methods}

\section{Study site and population}

A retrospective, multicentre cohort was established in the emergency departments (EDs) of three Taiwan hospitals during the period from Jan 2016 to Dec 2019. Study hospitals included a university-affiliated medical centre ( 1400 beds) and two teaching hospitals ( 380 and 460 beds, respectively). The adult patients (aged $\geq 18$ years) with community-onset bactereamia diagnosed in the ED were enrolled. The study was approved by the institutional review board of each participating hospital. Partial information in the present cohort has been recently published [17].

Patients sampled with blood cultures (BCs) during the ED stay were retrieved from a computer database. Of adults recognized with the $\mathrm{BC}$ growth, patients experiencing community-onset bacteremia were only eligible, after the exclusion of patients with contaminated BCs, those diagnosed with hospital-onset bactereamia or bactereamia prior to ED arrival, those with fungemia or mycobactereamia, and those had the uncertain outcome or incomplete clinical data within the study endpoint. Only the first episode of each patient participator, if multiple bactereamia episodes were reported in EDs, was included.

\section{Data collection}

By reviewing the electronic and paper chart, a predetermined form was adapted to capture clinical information, such as patient demographics, severity (McCabe classification) and types of comorbidities, types and antimicrobial susceptibilities of causative microorganisms, bactereamia sources, types and duration of antimicrobial administration, image studies, types and timing of surgical or radiologic interventions, and patient outcomes. For the qSOFA and SIRS analysis, the worst value of vital signs, 
metal status, and laboratory data within 24 hours after ED arrival was collected. All the clinical data were randomly retrieved by one ED physician and another infectious disease-trained physician, and these two authors inspected and discussed the medical records together for consensus, if any discrepancies were discovered. The study endpoint was all-cause mortality within 30 days after ED arrival (i.e., bactereamia onset).

\section{Microbiological methods}

The BC bottle was incubated in a BACTEC 9240 instrument (Becton Dickinson Diagnostic Systems, Sparks, MD, USA) for 5 days. Bacterial species was identified through the Vitek 2 system (bioMe'rieux, Durham, NC). Antimicrobial susceptibilities were determined by the broth microdilution method based on the contemporary CLSI standard [18]. To ensure the administration timing of appropriate antimicrobials in each bactereamia episode, all causative microorganisms in each bacteremia episode were prospectively stored for the susceptibility test. If a patient empirically treated by an antibiotic which was not included in the antimicrobial susceptibility test originally offered by the study hospital, the susceptibility to the indicated agent was retrospectively examined.

\section{Definitions}

After the exclusion of contaminant sampling, bactereamia was defined as bacterial growth in BCs drawn from peripheral or central venipuncture. The growth of potentially contaminating microorganisms in BCs, such as Propionibacterium species, Bacillus species, Micrococcus species, coagulase-negative staphylococci, and Gram-positive bacilli, was considered to be the contaminant sampling in accordance with previous criteria [19]. The onset place of the bactereamia episode within the community was regarded as community-onset bactereamia [20,21], which includes community- and long-term healthcareassociated bactereamia. Polymicrobial bactereamia was defined as the isolation of $\geq$ two microbial species from one bactereamia episode

As previously described $[13,14]$, antimicrobial administration was regarded as appropriate if the following criteria were totally fulfilled: (i) the antibiotic was in vitro active against all causative pathogens isolated from one bacteremia episode according to the 2020 CLSI breakpoint [18]; (ii) the antimicrobial dosage and route was administered as the recommendations issued by the Sanford Guide to Antimicrobial Therapy 2020 [22]. The hour between the ED triage and the initiation of appropriate antimicrobials was calculated as the time-to-appropriate antibiotic $[13,14]$. The time-to-appropriate antibiotic $\geq 24$ hours was regarded as inappropriate administration of empirical antimicrobial therapy (EAT).

As indicated by the Surviving Sepsis Campaign (SSC) [16], complicated bactereamia was defined by determination of whether that the bactereamia source is amenable to source control, such as the drainage of an abscess or obstructive tract, debridement of infected necrotic tissue, removal of a potentially infected device, and definitive control of a source of ongoing microbial contamination. As previously described $[23,24]$, the appropriateness of specific surgical or percutaneous source control for complicated bactereamia was determined by infectious disease-trained physicians. The period from 
bactereamia onset (i.e., ED triage) to appropriate source control was regarded as the time-to-source control. Patients not received appropriate source control during the period of intravenous antimicrobial therapy were regarded as recipients with inadequate source control.

Solid tumors and hematological malignancies were grouped as malignancies. A previous delineated system (McCabe classification) was assessed as the comorbid prognosis [25]. The bacteremia sources was determined by established definitions of the Centers for Disease Control and Prevention [26]. The SIRS includes the heart rate $>90 / \mathrm{min}$, respiratory rate $>20 / \mathrm{min}$, body temperature $<36^{\circ} \mathrm{C}$ or $>38^{\circ}$, and peripheral white blood cell count $<4000 / \mathrm{mm}^{3},>12,000 / \mathrm{mm}^{3}$, or $>10 \%$ immature bands [27]. The qSOFA includes the respiratory rate $\geq 22 / \mathrm{min}$, systolic blood pressure $\leq 100 \mathrm{mmHg}$, and alteration in conscious status [28].

\section{Statistical analysis}

The Statistical Package for the Social Science for Windows (version 23.0, Chicago, Illinois, USA) was performed for statistical analyses. Continuous variables were presented as the median and interquartile range (IQR) and compared by the t-test. Categorical variables were expressed as numbers and percentages and compared using the Chi-square test or Fisher's exact test. Using a stepwise, backward logistic regression model, all variables of 30-day mortality with $P<0.05$ recognized by the univariate analysis were together processed to recognize the independent determinant of 30-day crude mortality. The Kaplan-Meier curve and Cox regression model was examined to compare the adverse effect of inappropriate EAT or inadequate source control on 30-day prognoses of patients categorized by qSOFA or SIRS scores, after adjustment of all the independent determinants of 30-day crude mortality. A $P$ value $<$ 0.05 was considered significant. A c-statistic (area under ROC [receiver operating characteristic] curve) was calculated as the ability of qSOFA and SIRS scores to discriminate between survivors and fatal patients.

\section{Results}

\section{Demographics and clinical characteristics of the overall cohort}

According to the inclusion and exclusion criteria (Fig. 1), the total of 3,898 adults having communityonset bactereamia were enrolled in the present cohort. The median (IQR) age of overall patients was 70 (57-80) years, and male patients (2,018 patients, $51.8 \%)$ were predominant. The median (IQR) lengths of ED stay and hospitalization were 15.0 (5.4-26.4) hours and 10 (6-18) days, respectively. Patients experiencing complicated bactereamia accounted for $19.9 \%$ (775 patients) of the entire cohort. Patients initially presented with SIRS or qSOFA $\geq 2$ respectively accounted for $92.8 \%$ (3,619 patients) or $46.9 \%$ $(1,927)$ of the overall cohort. The 15-day and 30-day crude mortality rate was $13.6 \%$ (530 patients) and $17.2 \%$ (670), respectively. 
Of the total 3,898 patients, common comorbidities included hypertension (1,915 patients, $49.1 \%)$, diabetes mellitus $(1,491,38.3 \%)$, malignancies $(1,211,31.1 \%)$, neurological disorders $(956,24.5 \%)$, chronic kidney diseases $(756,19.4 \%)$, liver cirrhosis $(478,12.3 \%)$, coronary artery diseases $(391,10.0 \%)$, heart failure $(359,9.2 \%)$, urological diseases $(341,8.7 \%)$, and chronic obstructive pulmonary diseases $(214,5.5 \%)$. The leading source of bactereamia was urinary tract infections $(1,227,31.5 \%)$, followed by pneumonia $(648,16.6 \%)$, skin and soft-tissue infections $(438,11.2 \%)$, intra-abdominal infections (433, $11.1 \%)$, biliary tract infections $(322,8.3 \%)$, primary bactereamia $(287,7.4 \%)$, bone and joint infections $(152,3.9 \%)$, vascular-line infections (144, 3.7\%), liver abscess (138, 3.5\%), and infective endocarditis (117, $3.0 \%)$.

Because of 390 episodes of polymicrobial bactereamia, the total 4,398 causative microorganisms were identified. The leading ten microorganisms included Escherichia coli (1,528 isolates, 34.7\%), Klebsiella pneumoniae $(669,15.2 \%)$, Streptococcus species $(605,13.8 \%)$, Staphylococcus aureus $(511,11.6 \%)$, Pseudomonas species (138, 3.1\%), Enterococcus species (130, 3.0\%), Proteus species (104, 2.4\%), Enterobacter species (101, 2.3\%), Salmonella species (66, 1.5\%), and Aeromonas species (50, 1.1\%).

\section{The time-to-appropriate antibiotic and time-to-source control}

The median (IRQ) of the time-to-appropriate antibiotic and time-to-source control was $2(1-11)$ hours and $2(1-10)$ days, respectively. The period of time-to-appropriate antibiotic in patients initially presented with SIRS scores of $\geq 2$ (median, 2 vs. 67 hours, $P<0.001$ ) and qSOFA scores of $\geq 2$ (median, 4 vs. 36 hours, $P<0.001$ ) was significantly shorter than those with SIRS scores of $<2$ and qSOFA scores of $<2$ (Fig. 2A), respectively. Notably, the time-to-appropriate antibiotic in patients initially presented with SIRS scores of $\geq 2$ remained significant shorter than those with qSOFA scores of $\geq 2$ (median, 2 vs. 4 hours, $P<0.001$ )

Similarly, the period of the time-to-source control in patients initially with SIRS scores of $\geq 2$ (median, 2 vs. 9 hours, $P<0.001$ ) was significantly shorter than those with SIRS scores of $<2$ (Fig. 2B). However, the period of the time-to-source control between patients initially experienced qSOFA scores of $\geq 2$ and those with qSOFA scores of $<2$ did not differ significantly (median, 2 vs. 2 hours, $P=0.89$ ), as shown in Fig. 2B. Of note, the period of the time-to-source control in patients initially with SIRS scores of $\geq 2$ (median, $2 \mathrm{vs}$. 3 hours, $P=0.003$ ) was significantly shorter than those with qSOFA scores of $\geq 2$ (Fig. 2B).

\section{Clinical predictors of 30-day mortality}

The association of numerous clinical covariates, including patient demographics, the appropriateness of empirical antimicrobial therapy or source control, major bactereamia sources, comorbidity severity, major comorbidities, and the major causative pathogen, with 30-day mortality were examined using univariate analysis (Table 1). The following variables were positively associated with 30-day mortality: the elderly, male patients, nursing-home residents, inappropriate EAT, inadequate source control, bactereamic pneumonia, polymicrobial bactereamia, causative microorganisms of Klebsiella pneumoniae, Staphylococcus aureus, or Pseudomonas species, fatal comorbidities (McCabe classification), and 
underlying malignancies, neurological diseases, or liver cirrhosis. Otherwise, several factors, including bactereamia caused by urinary tract infections, biliary tract infections, or liver abscess, $E$. coli bactereamia, and comorbid hypertension, were protective factors against 30-day crude mortality. 
Table 1

Predictors of 30-day crude mortality in patients with community-onset bacteremia

\begin{tabular}{|c|c|c|c|c|c|c|}
\hline \multirow[t]{2}{*}{ Variables } & \multicolumn{2}{|c|}{ Patient numbers (\%) } & \multicolumn{2}{|c|}{ Univariate analysis } & \multicolumn{2}{|c|}{ Multivariate analysis } \\
\hline & $\begin{array}{l}\text { Death, } \\
n=670\end{array}$ & $\begin{array}{l}\text { Survival, } \\
\mathrm{n}=3228\end{array}$ & $\begin{array}{l}\mathrm{OR}(95 \% \\
\mathrm{Cl})\end{array}$ & $\begin{array}{l}P \\
\text { value }\end{array}$ & $\begin{array}{l}\text { Adjusted } \\
\text { OR (95\% } \\
\mathrm{Cl})\end{array}$ & $\begin{array}{l}P \\
\text { value }\end{array}$ \\
\hline \multicolumn{7}{|l|}{ Patient demographics } \\
\hline The elderly, $\geq 65$ years & $\begin{array}{l}442 \\
(66.0)\end{array}$ & $\begin{array}{l}1918 \\
(59.4)\end{array}$ & $\begin{array}{l}1.32 \\
(1.11- \\
1.58)\end{array}$ & 0.002 & $\begin{array}{l}1.28(1.04- \\
1.58)\end{array}$ & 0.02 \\
\hline Gender, male & $\begin{array}{l}394 \\
(58.8)\end{array}$ & $\begin{array}{l}1624 \\
(50.3)\end{array}$ & $\begin{array}{l}1.41 \\
(1.19- \\
1.67)\end{array}$ & $<0.001$ & NS & NS \\
\hline Nursing-home residents & $\begin{array}{l}94 \\
(14.0)\end{array}$ & $155(4.8)$ & $\begin{array}{l}3.24 \\
(2.47- \\
4.24)\end{array}$ & $\dot{0} 001$ & $\begin{array}{l}1.99(1.42- \\
2.78)\end{array}$ & <. \\
\hline $\begin{array}{l}\text { Inappropriate empirical } \\
\text { antimicrobial therapy }\end{array}$ & $\begin{array}{l}117 \\
(26.4)\end{array}$ & $624(19.3)$ & $\begin{array}{l}1.50 \\
(1.24- \\
1.82)\end{array}$ & $\dot{0} 001$ & $\begin{array}{l}1.59(1.27- \\
1.99)\end{array}$ & <. \\
\hline Inadequate source control & $42(6.3)$ & $91(2.8)$ & $\begin{array}{l}2.31 \\
(1.58- \\
3.36)\end{array}$ & $\hat{0} .001$ & $\begin{array}{l}3.36(2.19- \\
5.17)\end{array}$ & $<.001$ \\
\hline \multicolumn{7}{|l|}{ Major bacteremia sources } \\
\hline Pneumonia & $\begin{array}{l}299 \\
(44.6)\end{array}$ & $349(10.8)$ & $\begin{array}{l}6.65 \\
(5.51- \\
8.03)\end{array}$ & $\hat{0} .001$ & $\begin{array}{l}4.35(3.46- \\
5.45)\end{array}$ & $<.001$ \\
\hline Intra-abdominal & $\begin{array}{l}75 \\
(11.2)\end{array}$ & $358(11.1)$ & $\begin{array}{l}1.01 \\
(0.78- \\
1.32)\end{array}$ & 0.94 & - & - \\
\hline Urinary tracts & $\begin{array}{l}72 \\
(10.7)\end{array}$ & $\begin{array}{l}1155 \\
(35.8)\end{array}$ & $\begin{array}{l}0.22 \\
(0.17- \\
0.28)\end{array}$ & $\hat{0} .001$ & $\begin{array}{l}0.35(0.26- \\
0.47)\end{array}$ & <. 001 \\
\hline Skin and soft-tissue & $61(9.1)$ & $377(11.7)$ & $\begin{array}{l}0.76 \\
(0.527- \\
1.01)\end{array}$ & 0.06 & - & - \\
\hline Biliary tracts & $30(4.5)$ & $292(9.0)$ & $\begin{array}{l}0.47 \\
(0.32- \\
0.69)\end{array}$ & $\hat{0} .001$ & $\begin{array}{l}0.46(0.30- \\
0.70)\end{array}$ & <. 001 \\
\hline
\end{tabular}

$\mathrm{Cl}=$ confidence interval; $\mathrm{NS}$ = not significant (after processing the backward multivariate regression); $\mathrm{OR}=$ odds ratio. 


\begin{tabular}{|c|c|c|c|c|c|c|}
\hline \multirow[t]{2}{*}{ Variables } & \multicolumn{2}{|c|}{ Patient numbers (\%) } & \multicolumn{2}{|c|}{ Univariate analysis } & \multicolumn{2}{|c|}{ Multivariate analysis } \\
\hline & $\begin{array}{l}\text { Death, } \\
n=670\end{array}$ & $\begin{array}{l}\text { Survival, } \\
\mathrm{n}=3228\end{array}$ & $\begin{array}{l}\mathrm{OR}(95 \% \\
\mathrm{Cl})\end{array}$ & $\begin{array}{l}P \\
\text { value }\end{array}$ & $\begin{array}{l}\text { Adjusted } \\
\text { OR (95\% } \\
\mathrm{Cl})\end{array}$ & $\begin{array}{l}P \\
\text { value }\end{array}$ \\
\hline Liver abscess & $8(1.2)$ & $130(4.0)$ & $\begin{array}{l}0.29 \\
(0.14- \\
0.59)\end{array}$ & $\hat{0} .001$ & $\begin{array}{l}0.32(0.15- \\
0.69)\end{array}$ & 0.004 \\
\hline Polymicrobial bacteremia & $\begin{array}{l}119 \\
(17.8)\end{array}$ & $271(8.4)$ & $\begin{array}{l}2.36 \\
(1.87- \\
2.98)\end{array}$ & $<.001$ & NS & NS \\
\hline \multicolumn{7}{|l|}{$\begin{array}{l}\text { Major causative } \\
\text { microorganisms }\end{array}$} \\
\hline Escherichia coli & $\begin{array}{l}167 \\
(24.9)\end{array}$ & $\begin{array}{l}1360 \\
(42.1)\end{array}$ & $\begin{array}{l}0.46 \\
(0.38- \\
0.55)\end{array}$ & $<001$ & NS & NS \\
\hline Klebsiella pneumoniae & $\begin{array}{l}149 \\
(22.2)\end{array}$ & $519(16.1)$ & $\begin{array}{l}1.49 \\
(1.22- \\
1.83)\end{array}$ & $<001$ & $\begin{array}{l}1.24(0.97- \\
1.59)\end{array}$ & 0.08 \\
\hline Staphylococcus aureus & $\begin{array}{l}121 \\
(19.1)\end{array}$ & $389(12.1)$ & $\begin{array}{l}1.61 \\
(1.29- \\
2.01)\end{array}$ & $<.001$ & NS & NS \\
\hline Streptococcus species & $\begin{array}{l}108 \\
(16.1)\end{array}$ & $480(14.9)$ & $\begin{array}{l}1.10 \\
(0.88- \\
1.38)\end{array}$ & 0.41 & - & - \\
\hline Pseudomonas species & $45(6.7)$ & $93(2.9)$ & $\begin{array}{l}2.43 \\
(1.68- \\
3.50)\end{array}$ & $<.001$ & NS & NS \\
\hline Enterococcus species & $24(3.6)$ & $106(3.3)$ & $\begin{array}{l}1.09 \\
(0.70- \\
1.72)\end{array}$ & 0.70 & - & - \\
\hline $\begin{array}{l}\text { Fatal comorbidities } \\
\text { (McCabe classification) }\end{array}$ & $\begin{array}{l}312 \\
(46.6)\end{array}$ & $716(22.2)$ & $\begin{array}{l}3.06 \\
(2.57- \\
3.64)\end{array}$ & $\dot{0} 001$ & $\begin{array}{l}2.39(1.89- \\
3.02)\end{array}$ & <. 001 \\
\hline \multicolumn{7}{|l|}{ Major comorbidities } \\
\hline Malignancies & $\begin{array}{l}308 \\
(46.0)\end{array}$ & $903(28.0)$ & $\begin{array}{l}2.19 \\
(1.85- \\
2.60)\end{array}$ & $\hat{0} .001$ & $\begin{array}{l}1.40(1.11- \\
1.76)\end{array}$ & 0.004 \\
\hline Hypertension & $\begin{array}{l}300 \\
(44.8)\end{array}$ & $\begin{array}{l}1615 \\
(50.0)\end{array}$ & $\begin{array}{l}0.81 \\
(0.69- \\
0.96)\end{array}$ & 0.01 & $\begin{array}{l}0.84(0.69- \\
1.03)\end{array}$ & 0.10 \\
\hline \multicolumn{7}{|c|}{$\mathrm{Cl}=$ confidence interval; $\mathrm{NS}=$ not significant (after processing the backward multivariate regression); } \\
\hline OR $=$ odds ratio. & & & & & & \\
\hline
\end{tabular}




\begin{tabular}{|c|c|c|c|c|c|c|}
\hline \multirow[t]{2}{*}{ Variables } & \multicolumn{2}{|c|}{ Patient numbers (\%) } & \multicolumn{2}{|c|}{ Univariate analysis } & \multicolumn{2}{|c|}{ Multivariate analysis } \\
\hline & $\begin{array}{l}\text { Death, } \\
n=670\end{array}$ & $\begin{array}{l}\text { Survival, } \\
\mathrm{n}=3228\end{array}$ & $\begin{array}{l}\text { OR }(95 \% \\
\mathrm{Cl})\end{array}$ & $\begin{array}{l}P \\
\text { value }\end{array}$ & $\begin{array}{l}\text { Adjusted } \\
\text { OR (95\% } \\
\text { CI) }\end{array}$ & $\begin{array}{l}P \\
\text { value }\end{array}$ \\
\hline Diabetes mellitus & $\begin{array}{l}238 \\
(35.5)\end{array}$ & $\begin{array}{l}1253 \\
(38.8)\end{array}$ & $\begin{array}{l}0.87 \\
(0.73- \\
1.03)\end{array}$ & 0.11 & - & - \\
\hline Neurological diseases & $\begin{array}{l}217 \\
(32.4)\end{array}$ & 739 (22.9) & $\begin{array}{l}1.61 \\
(1.35- \\
1.93)\end{array}$ & $\begin{array}{l}< \\
0.001\end{array}$ & $\begin{array}{l}1.35(1.06- \\
1.71)^{-}\end{array}$ & 0.02 \\
\hline Chronic kidney diseases & $\begin{array}{l}134 \\
(20.0)\end{array}$ & $622(19.3)$ & $\begin{array}{l}1.05 \\
(0.85- \\
1.29)\end{array}$ & 0.66 & - & - \\
\hline Liver cirrhosis & $\begin{array}{l}116 \\
(17.3)\end{array}$ & $362(11.2)$ & $\begin{array}{l}1.66(1.32 \\
=-2.08)\end{array}$ & <. 001 & $\begin{array}{l}1.52(1.17- \\
1.99)\end{array}$ & 0.002 \\
\hline Coronary artery diseases & $\begin{array}{l}76 \\
(11.3)\end{array}$ & $315(9.8)$ & $\begin{array}{l}1.18 \\
(0.91- \\
1.54)\end{array}$ & 0.21 & - & - \\
\hline \multicolumn{7}{|c|}{$\mathrm{Cl}=$ confidence interval; NS = not significant (after processing the backward multivariate regression); } \\
\hline OR = odds ratio. & & & & & & \\
\hline
\end{tabular}

Furthermore, through the multivariate regression model (Table 1), numerous independent determinants of 30-day crude mortality were recognized: the elderly, nursing-home residents, inappropriate EAT, inadequate source control, bactereamic pneumonia, bactereamia due to urinary tract infections, biliary tract infections, or liver abscess, fatal comorbidities (McCabe classification), and comorbid malignancies, neurological diseases, or liver cirrhosis.

\section{Effects of inappropriate EAT and inadequate source control on prognoses of patients categorized by qSOFA or SIRS}

After adjustment of the independent predictors of 30-day mortality, recognized in Table 1, significant impacts of inappropriate EAT on 30-day crude mortality were exhibited in patients initially presented with SIRS scores of 2 and 3-4, but not in those of $0-1$ (Fig. 3A). Similarly, significant effects of inadequate source control on prognoses were evidenced in patients initially with SIRS scores of 2 and 3-4, but not in those of $0-1$ (Fig. 3B).

Notably, adverse impacts of inappropriate EAT (Fig. 4A) and inadequate source control (Fig. 4B) on 30day crude mortality were all significant in patients initially experienced qSOFA scores of $0-1,2$, and 3 , after adjusting all the independent determinates of 30-day mortality. 


\section{The discrimination in predicting 30-day mortality by SIRS and qSOFA scores}

For prediction of 30-day crude mortality (Fig. 5), the area under the ROC curve is 0.830 ( $95 \%$ confidence interval [Cl], 0.812-0.848; $P<0.001)$ in the qSOFA score and $0.712(95 \% \mathrm{Cl}, 0.689-0.735 ; P<0.001)$ in the SIRS score; thus the ability to discriminate between survivors and fatal patients was proper in the SIRS score and excellent in the qSOFA score.

\section{Discussion}

Generally, little consensus has been reached regarding the potential advantages of prompt administration of appropriate antimicrobial therapy in cases of bloodstream infection. Some studies have reported that such treatment has no effect $[29,30]$, whereas numerous investigations have evidenced significant reductions in fatality [13,31,32]. Consistent with previous ED-based investigations [13-15], the prompt initiation of effective antimicrobial therapy was a crucial factor associated with favourable prognoses in our cohort. Moreover, the findings of this study evidence a strong association between adequate source control and favourable outcomes, suggesting the need for updating the SSC recommendations to include timely evaluation of the coexistence of complicated infections and the acquisition of successful source control to achieve rapid stabilisation and improved prognoses [16].

Sepsis is more often recognised from associated organ dysfunction than from less easily identified infections. Thus, sepsis can be defined as "life-threatening organ dysfunction caused by dysregulated host responses to infections" [16]. Traditionally, The original consensus statement on the definition of sepsis issued by the American College of Chest Physicians/Society of Critical Care Medicine in 1992 defined sepsis as a combination of SIRS criteria and the presence of infection [33]. However, this definition recently raised confusion and discussion, because SIRS criteria are not themselves typical features of infections and thus result in low specificity for sepsis diagnoses. Accordingly, organ dysfunction was recently characterized by Sepsis-3 Task Force and they released a consensus statement redefining the clinical syndrome of sepsis, which eliminate the SIRS concept and are based on confirmed or suspected infection with a change in SOFA scores of $\geq 2$. However, the recently published consensus definitions for sepsis have led to controversy and prompted much discussion [10,11]. In conformity with the previous consideration that the new sepsis definition de-emphasizes intervention at earlier stages of sepsis [10], our principal finding indicated that the sepsis redefinition was suitable and unsafe, because delayed EAT administration and inadequate source control were demonstrated to remain a adverse impact on the short-term mortality of qSOFA-negative patients with bacteremia who had been characterised as non-septic at the early stage. Otherwise, the neglected effect of delayed EAT administration and inadequate source control on prognoses of non-septic patients, transitionally recognized by SIRS scores, was evidenced in our cohort.

The Sepsis-3 guidelines emphasise that the qSOFA can be easily and repeatedly performed and, more importantly, that it is more accurate than the SIRS score for predicting the mortality of patients with 
suspected sepsis outside of the ICU [28]. Consistent with relevant reports indicating that the qSOFA has greater discrimination ability for determining in-hospital mortality than the previous definition of sepsis $[34,35]$, the present study demonstrated that the qSOFA demonstrates better performance for predicting short-term mortality compared with SIRS criteria. Nevertheless, thoughtful criticisms have also been articulated for the clinical application of the qSOFA. Many believe that the greater specificity of the qSOFA compared with the SIRS criteria may lead to delays in the initiation of treatment because of the expense of lower qSOFA sensitivity [10]. Consistent with this consideration, the period gap until appropriate antibiotic administration and successful source control was longer in patients with bacteremia identified according to the qSOFA in our cohort compared with that in patients identified according to SIRS criteria.

Bacteremia is associated with high morbidity and mortality, with a crude mortality rate of up to $35 \%$ and costs of up to $\$ 37,000$ per case [36], and a population-based investigation revealed that the annual incidence of community-onset bacteremia may range between 43 and 154 per 100,000 [21]. We selected patients with community-onset bacteremia as the target population and the ED as the research setting because we believe that the burden of community-onset bloodstream infections is comparable in magnitude to that which ED physicians face and manage daily when treating conditions such as acute stroke, acute coronary syndrome, and major trauma.

Our study has certain limitations. First, the retrospective nature of this study made it prone to recall bias during data collection. To reduce this bias, all clinical information was randomly retrieved by two authors who inspected medical records together to solve discrepancies in our study design. Second, regarding the retrospective nature of the analysis of the effect of different variables on patient survival, few patients with uncertain mortality or incomplete clinical information were excluded; thus, selection bias was negligible. Finally, because all of the study hospitals were located in southern Taiwan, our findings may not be generalisable to other populations, which may vary in terms of different causative microorganisms or degree of bacteremia severity. However, the present study is the first to provide the external validation of the Sepsis-3 guidelines in bacteremia patients and thereby to compare the effect of treatment efforts on prognosis of those categized by traditional and revised sepsis definitions.

\section{Conclusion}

For patients with community-onset bacteraemia, the qSOFA has greater discrimination ability for determining fatal patients from survivors than the SIRS score. However, the new definition of sepsis, assessed according to the qSOFA score, might impede treatment efforts. Notably, the delayed treatment might result in the substantial disadvantage because the adverse effects of delayed EAT administration and inadequate source control on unfavourable outcomes clearly remained significant in qSOFA-negative patients classified as non-septic. Accordingly, adopting a stricter definition that requires further progression along the sepsis pathway to avoid delays in intervention administration is necessary.

\section{Abbreviations}


AOR: adjusted odds ratio; BC: blood culture; CLSI: Clinical and Laboratory Standards Institute; EAT: empirical antimicrobial therapy; ED: emergency department; IQR: interquartile range; qSOFA: quick Sequential Organ Failure Assessment; SIRS: systemic inflammatory response syndrome; SOFA: Sequential Organ Failure Assessment; SSC: Surviving Sepsis Campaign; ROC: receiver operating characteristic.

\section{Declarations}

\section{Acknowledgements}

We would like to thank for providing experimental space and facilities by the Diagnostic Microbiology and Antimicrobial Resistance Laboratory, National Cheng Kung University Hospital, College of Medicine, National Cheng Kung University, Tainan, Taiwan.

\section{Funding}

This study was partially supported by research grants from the Ministry of Science and Technology (MOST 109-2314-B-006-097), the Ministry of Health and Welfare (MOHW109-TDU-B-211-114003), Sin-Lau Hospital (SLH-M106-01, SLH-M107-02, SLH-M108-01, and SLH-109-04) and National Cheng Kung University Hospital (NCKUH-10909031), Tainan, Taiwan.

\section{Availability of data and materials}

Available from the corresponding author on reasonable request.

\section{Authors' contributions}

$\mathrm{CCL}$ and WK conceived the study idea and designed the study. $\mathrm{CCL}, \mathrm{PC}, \mathrm{MH}, \mathrm{CH}$, and $\mathrm{CHL}$ supervised the data collection and chart reviews. $\mathrm{CCL}, \mathrm{PC}, \mathrm{MH}$, and WK provided methodological and statistical advice on study design and data analysis. CCL and YH provided the data of microbiologic analyses. CCL drafted this manuscript. CHL and WK provided expertise in infectious disease and revised it carefully from a professional point of view. All authors read and approved the final manuscript.

\section{Competing interests}

The authors declare no conflict of interest.

\section{Consent for publication}

All authors have provided consent for publication of the manuscript.

\section{Ethical approval}

The study was approved by the institutional review board of National Cheng Kung University Hospital (BER-109-144), Madou Sin-Lau Hospital (SLH 9919-108-006), and Tainan Sin-Lau Hospital (SLH 9919-108- 
009); and the requirement of obtaining informed consent was waived.

\section{References}

1. Gaieski DF, Edwards JM, Kallan MJ, Carr BG. Benchmarking the incidence and mortality of severe sepsis in the United States. Crit Care Med. 2013;41:1167-74.

2. Seymour CW, Gesten F, Prescott HC, Friedrich ME, Iwashyna TJ, Phillips GS, et al. Time to treatment and mortality during mandated emergency care for sepsis. N Engl J Med. 2017;376:2235-44.

3. Ferrer R, Martin-Loeches I, Phillips G, Osborn TM, Townsend S, Dellinger RP, et al. Empiric antibiotic treatment reduces mortality in severe sepsis and septic shock from the first hour: results from a guideline-based performance improvement program. Crit Care Med. 2014;42:1749-55.

4. Kaukonen K-M, Bailey M, Pilcher D, Cooper DJ, Bellomo R. Systemic inflammatory response syndrome criteria in defining severe sepsis. N Engl J Med. 2015;372:1629-38.

5. Jones AE, Trzeciak S, Kline JA. The Sequential Organ Failure Assessment score for predicting outcome in patients with severe sepsis and evidence of hypoperfusion at the time of emergency department presentation. Crit Care Med. 2009;37:1649.

6. Levy MM, Evans LE, Rhodes A. The Surviving Sepsis Campaign Bundle: 2018 update. Intensive Care Med. 2018;44:925-8.

7. Giamarellos-Bourboulis EJ, Tsaganos T, Tsangaris I, Lada M, Routsi C, Sinapidis D, et al. Validation of the new Sepsis-3 definitions: proposal for improvement in early risk identification. Clinic Microbiol Infect. 2017;23:104-9.

8. Lind ML, Phipps Al, Mooney S, Liu C, Fohner A, Patel K, et al. Predictive value of three clinical criteria for sepsis (qSOFA, SIRS, and NEWS) with respect to short-term mortality in allogeneic hematopoietic cell transplant recipients with suspected infections. Clin Infect Dis. 2020 (on-line).

9. McNamara JF, Avent M, Stewart A, Kwan C, Paterson DL. Evaluation of quick sequential organ failure assessment and systemic inflammatory response syndrome in patients with gram negative bloodstream infection. Infect Dis Health. 2020;25:151-7.

10. Simpson SQ. New sepsis criteria: a change we should not make. Chest. 2016;149:1117-8.

11. Vincent J-L, Martin GS, Levy MM. qSOFA does not replace SIRS in the definition of sepsis. Crit Care. 2016;20:210.

12. Bates DW, Pruess KE, Lee TH. How bad are bacteremia and sepsis? Outcomes in a cohort with suspected bacteremia. Arch Intern Med. 1995;155:593-8.

13. Lee CC, Lee CH, Yang CY, Hsieh CC, Tang HJ, Ko WC. Beneficial effects of early empirical administration of appropriate antimicrobials on survival and defervescence in adults with community-onset bacteremia. Crit Care. 2019;23:363.

14. Lee CC, Lee $\mathrm{CH}$, Hong MY, Tang HJ, Ko WC. Timing of appropriate empirical antimicrobial administration and outcome of adults with community-onset bacteremia. Crit Care. 2017;21:119. 
15. Eliopoulos GM, Paterson DL, Rice LB. Empirical antibiotic choice for the seriously ill patient: are minimization of selection of resistant organisms and maximization of individual outcome mutually exclusive? Clin Infect Dis. 2003;36:1006-12.

16. Rhodes A, Evans LE, Alhazzani W, Levy MM, Antonelli M, Ferrer R, et al: Surviving Sepsis Campaign: International Guidelines for Management of Sepsis and Septic Shock: 2016. Intensive Care Med. 2017;43:304-77.

17. Lee CC, Yang CY, Su BA, Hsieh CC, Hong MY, Lee CH, Ko WC. The Hypotension Period after Initiation of Appropriate Antimicrobial Administration Is Crucial for Survival of Bacteremia Patients Initially Experiencing Severe Sepsis and Septic Shock. J Clin Med. 2020;9:2617.

18. Clinical and Laboratory Standards Institute. Performance standards for antimicrobial susceptibility testing; approved standard. $30^{\text {th }}$ informational supplement. CLSI document M100-S30. Wayne, PA: CLSI, 2020.

19. Lee CC, Lin WJ, Shih HI, Wu CJ, Chen PL, Lee HC, et al. Clinical significance of potential contaminants in blood cultures among patients in a medical center. J Microbiol Immunol Infect. 2007;40:438-44.

20. Hsieh CC, Chen PL, Lee CH, Yang CY, Lee CC, Ko WC. Definitive Cefazolin Therapy for Stabilized Adults with Community-Onset Escherichia coli, Klebsiella Species, and Proteus mirabilis Bacteremia: MIC Matters. J Clin Med. 2020;9:157.

21. Laupland KB, Church DL. Population-based epidemiology and microbiology of community-onset bloodstream infections. Clin Microbiol Rev. 2014;27:647-64.

22. Gilbert DN, Chambers HF, Eliopoulos GM, Saag MS, Pavia AT. Antibacterial Durg Dosage/Side Effects. The Sanford Guide to Antimicrobial Therapy 2020:106-124.

23. Chotiprasitsakul D, Han JH, Cosgrove SE, Harris AD, Lautenbach E, Conley AT, et al. Comparing the Outcomes of Adults With Enterobacteriaceae Bacteremia Receiving Short-Course Versus ProlongedCourse Antibiotic Therapy in a Multicenter, Propensity Score-Matched Cohort. Clin Infect Dis. 2018;66:172-7.

24. Sawyer RG, Claridge JA, Nathens AB, Rotstein OD, Duane TM, Evans HL, et al. Trial of short-course antimicrobial therapy for intraabdominal infection. N Engl J Med. 2015;372:1996-2005.

25. McCabe WR. Gram-negative bacteremia. Adv Intern Med. 1974;19:135-58.

26. Garner JS, Jarvis WR, Emori TG, Horan TC, Hughes JM. CDC definitions for nosocomial infections, 1988. Am J Infect Control. 1988;16:128-40.

27. Physicians ACoC, Committee SoCCMCC. American College of Chest Physicians/Society of Critical Care Medicine Consensus Conference: definitions for sepsis and organ failure and guidelines for the use of innovative therapies in sepsis. Crit Care Med. 1992;20:864-74.

28. Seymour CW, Liu VX, Iwashyna TJ, Brunkhorst FM, Rea TD, Scherag A, et al. Assessment of clinical criteria for sepsis: for the Third International Consensus Definitions for Sepsis and Septic Shock (Sepsis-3). JAMA. 2016;315:762-74. 
29. Lin MY, Weinstein RA, Hota B. Delay of active antimicrobial therapy and mortality among patients with bacteremia: impact of severe neutropenia. Antimicrob Agents Chemother. 2008;52:3188-94.

30. Corona A, Bertolini G, Lipman J, Wilson AP, Singer M. Antibiotic use and impact on outcome from bacteraemic critical illness: the BActeraemia Study in Intensive Care (BASIC). J Antimicrob Chemother. 2010;65:1276-85.

31. Ibrahim EH, Sherman G, Ward S, Fraser VJ, Kollef MH. The influence of inadequate antimicrobial treatment of bloodstream infections on patient outcomes in the ICU setting. Chest. 2000; 118:146-55.

32. Chen HC, Lin WL, Lin CC, Hsieh WH, Hsieh $\mathrm{CH}, \mathrm{Wu} \mathrm{MH}$, et al. Outcome of inadequate empirical antibiotic therapy in emergency department patients with community-onset bloodstream infections. J Antimicrob Chemother. 2013;68:947-53.

33. Bone RC, Balk RA, Cerra FB, Dellinger RP, Fein AM, Knaus WA, et al. Definitions for sepsis and organ failure and guidelines for the use of innovative therapies in sepsis. Chest. 1992;101:1644-55.

34. Finkelsztein EJ, Jones DS, Ma KC, Pabón MA, Delgado T, Nakahira K, et al. Comparison of qSOFA and SIRS for predicting adverse outcomes of patients with suspicion of sepsis outside the intensive care unit. Crit Care. 2017;21:73

35. Freund Y, Lemachatti N, Krastinova E, Van Laer M, Claessens Y-E, Avondo A, et al. Prognostic accuracy of Sepsis-3 criteria for in-hospital mortality among patients with suspected infection presenting to the emergency department. JAMA. 2017;317:301-8.

36. Anderson DJ, Kirkland KB, Kaye KS, Thacker PA, 2nd, Kanafani ZA, Auten G, et al. Underresourced hospital infection control and prevention programs: penny wise, pound foolish? Infect Control Hosp Epidemiol. 2007;28:767-73.

\section{Figures}


7,357 adults with growth of blood cultures in the emergency department (ED) of three hospitals between January 2016 and December 2019

\begin{tabular}{|c|c|}
\hline $\begin{array}{l}\text { Exclusion of } 773 \text { having hospital-onset } \\
\text { bacteremia or bacteremia diagnosed } \\
\text { prior to visiting the ED }\end{array}$ & $\begin{array}{l}\text { Exclusion of } 2,542 \text { with contaminant } \\
\text { sampling of blood culture, } 34 \text { with } \\
\text { fungemia, and } 11 \text { with mycobactereamia }\end{array}$ \\
\hline
\end{tabular}

3,997 adults with community-onset bacteremia

\begin{tabular}{|l|l|}
\hline & $\begin{array}{l}\text { Exclusion of } 65 \text { with incomplete clinical } \\
\text { information and } 34 \text { with uncertain } \\
\text { fatality within } 30 \text { days after bacteremia } \\
\text { onset }\end{array}$ \\
\hline 3,898 with community-onset bacteremia
\end{tabular}

\section{Figure 1}

Flowchart of patient selections. 

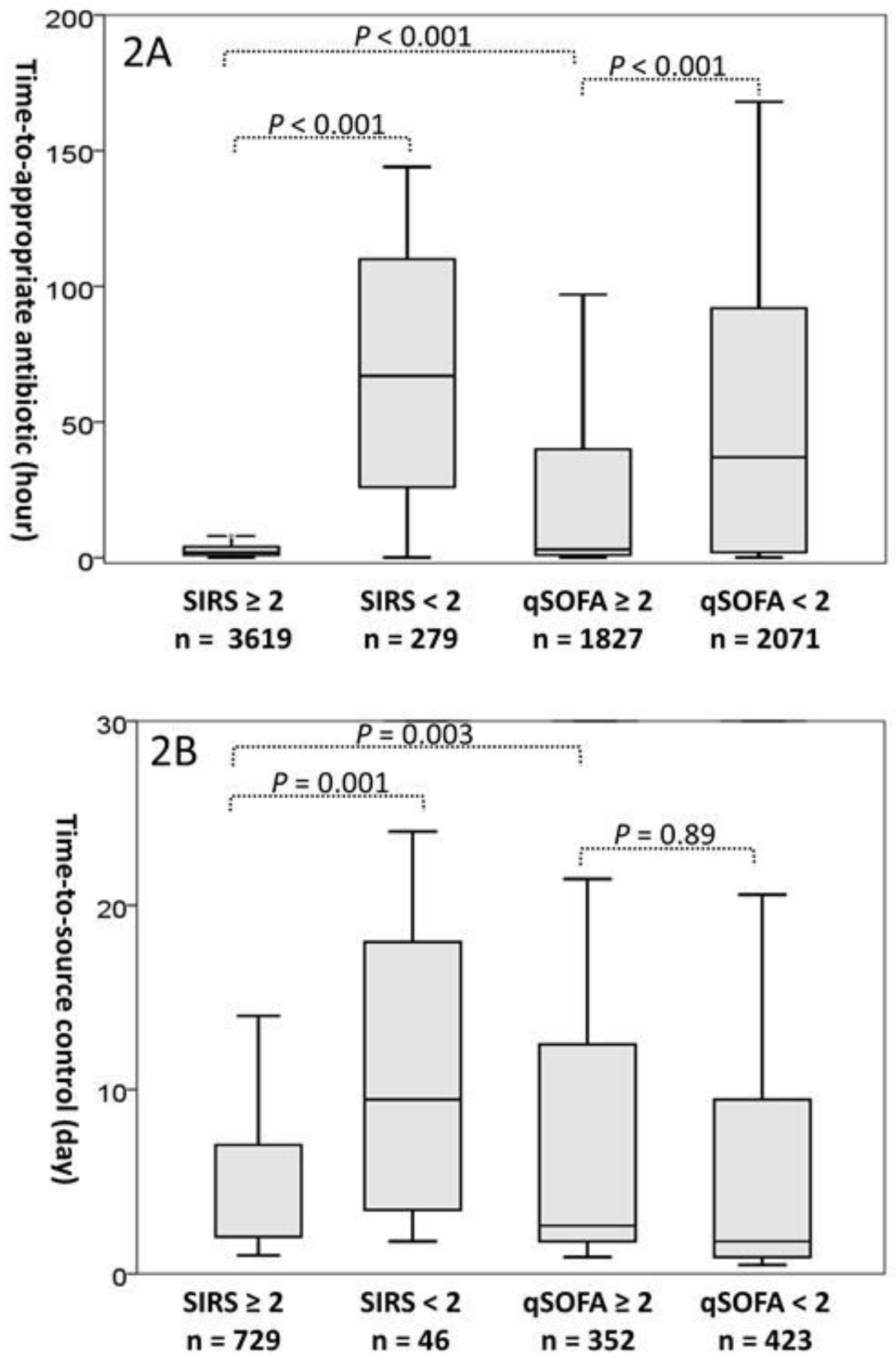

Figure 2

The time-to-appropriate antibiotic and time-to-source control* in patients with community-onset bacteremia, categorized by SIRS scores of $\geq 2$, SIRS $<2$, qSOFA $\geq 2$, and qSOFA $<2$. *Only 775 patients with complicated bacteremia were calculated. 

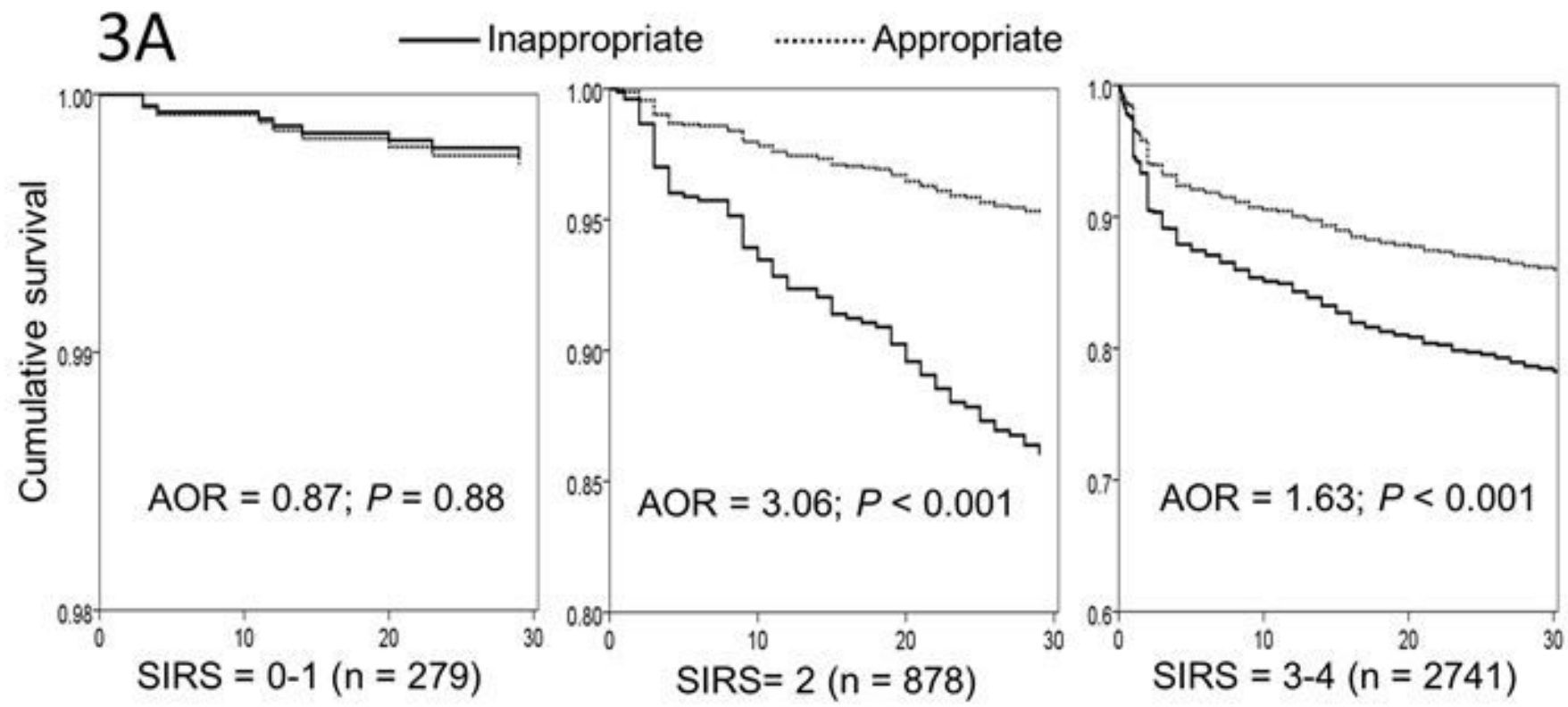

Days after the onset of bacteremia
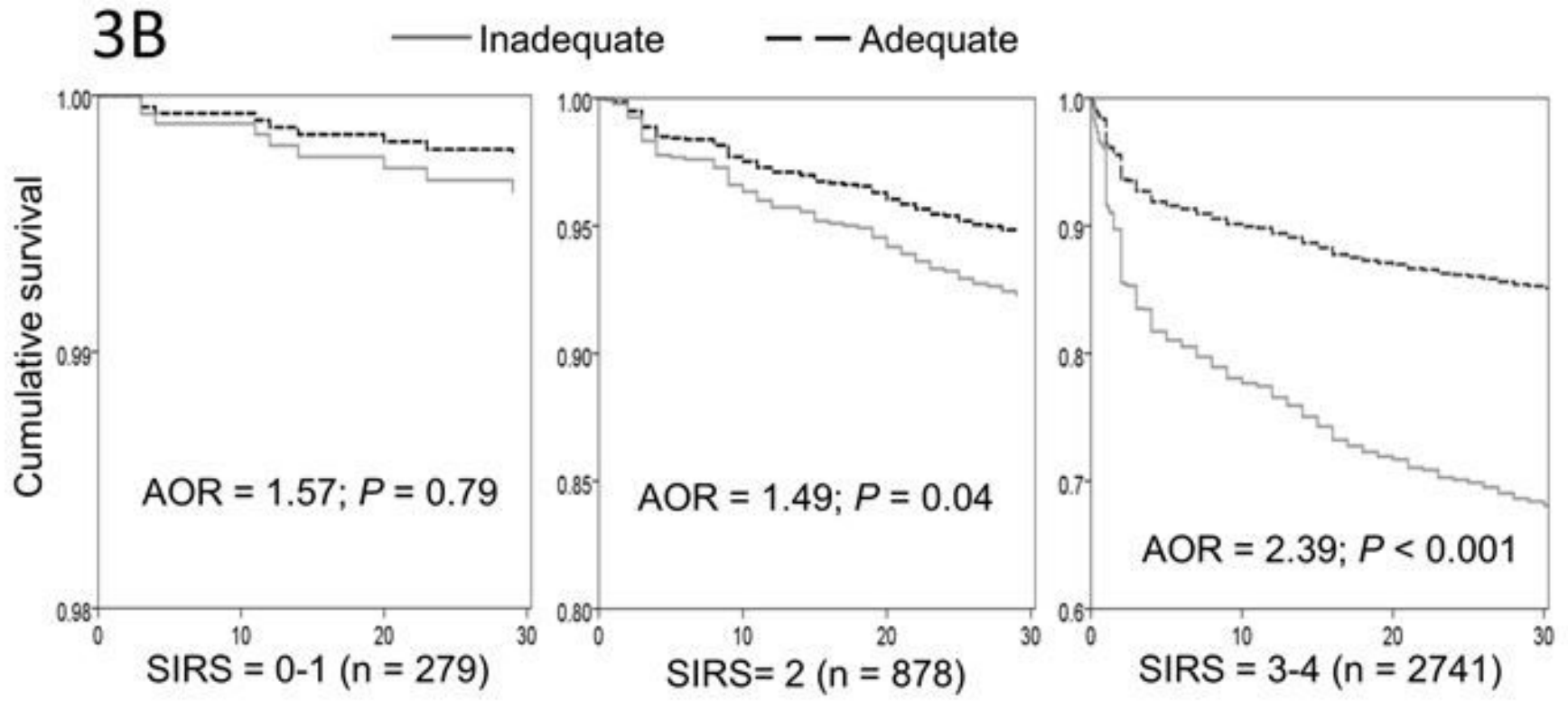

Days after the onset of bacteremia

\section{Figure 3}

Impacts of inappropriate empirical antimicrobial therapy (Figure 3A) and inadequate source control (Figure 3B) on 30-day mortality between bacteremia patients with varied categories of SIRS criteria, after adjustment of all independent determinants of 30-day mortality. 

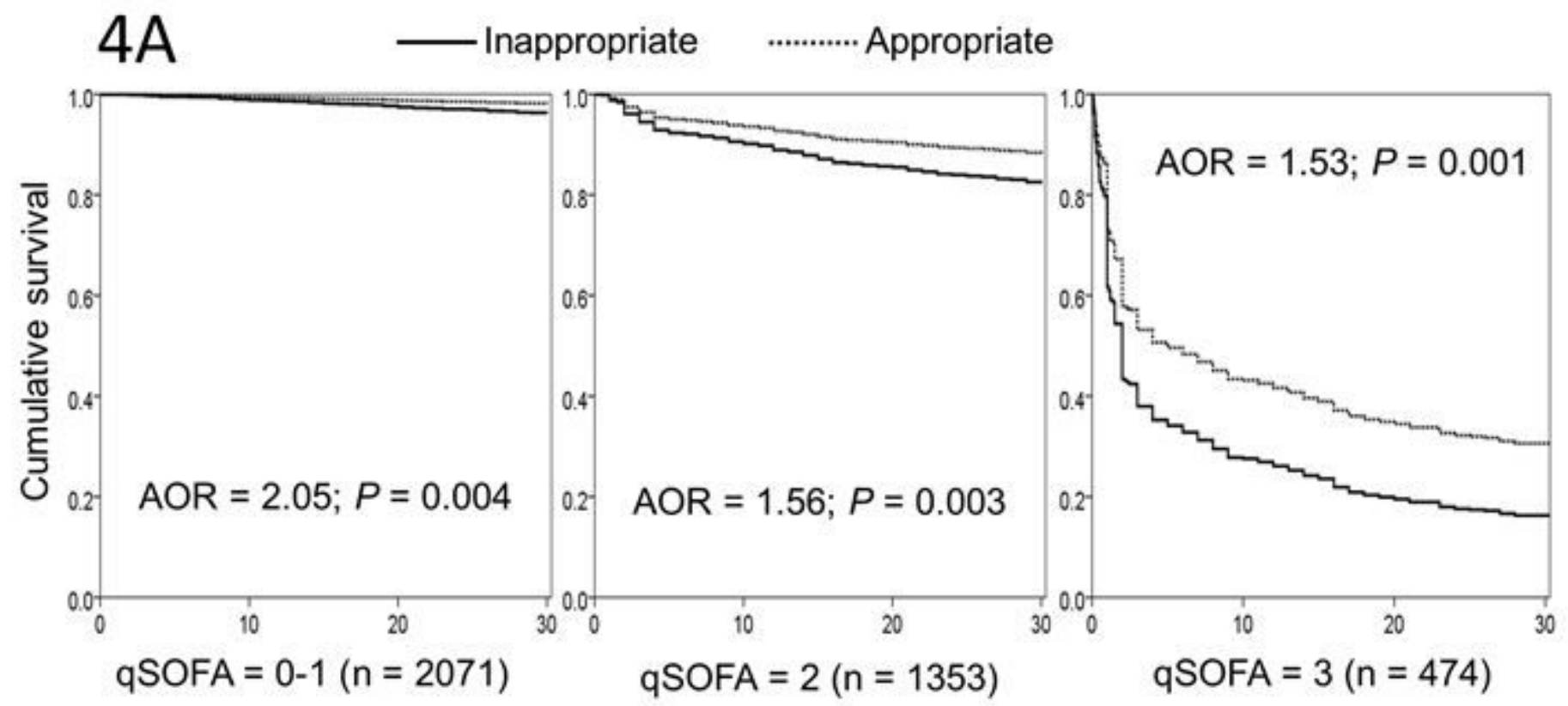

Days after the onset of bacteremia

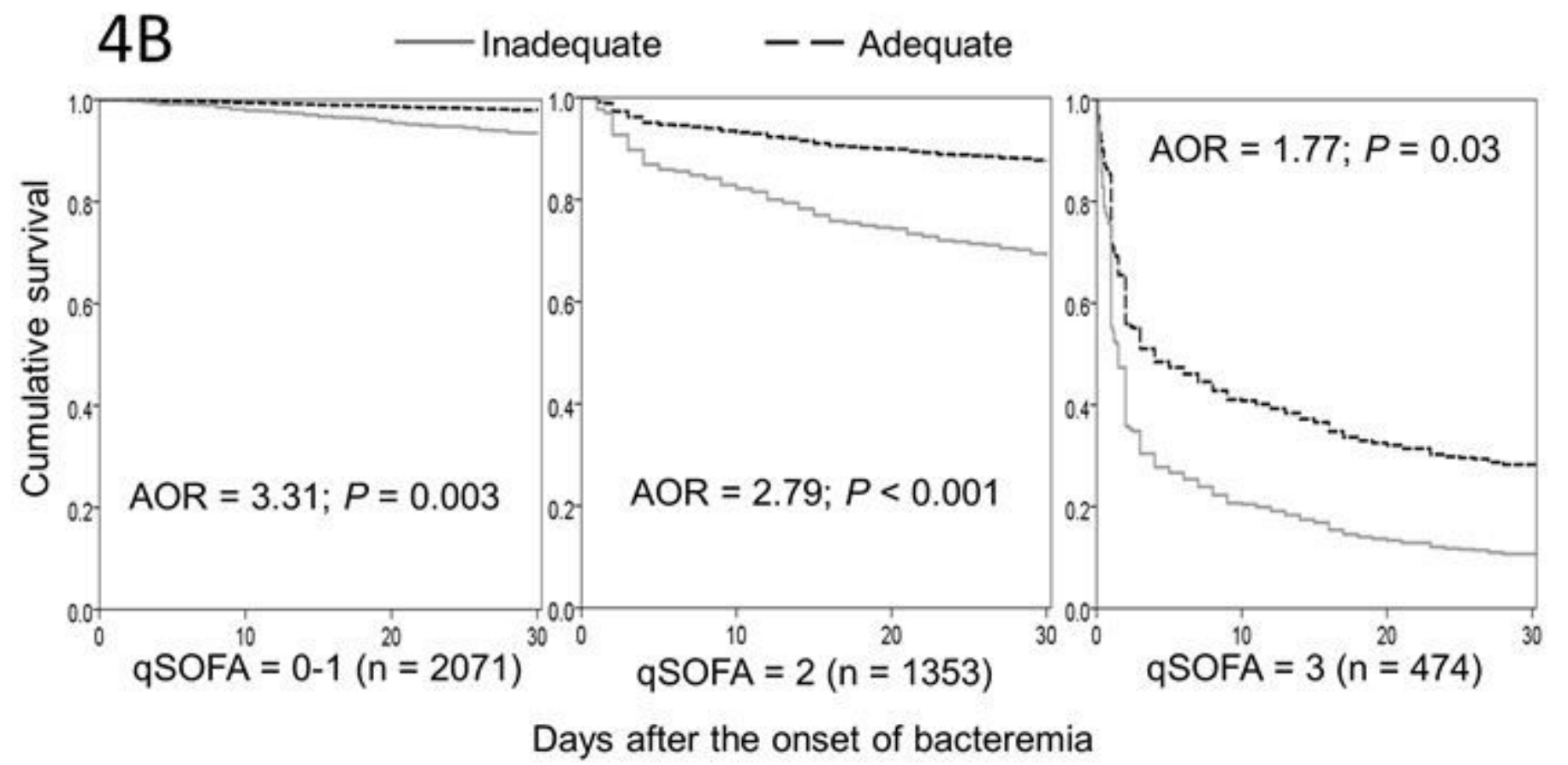

\section{Figure 4}

Impacts of inappropriate empirical antimicrobial therapy (Figure 4A) and inadequate source control (Figure 4B) on 30-day mortality between patients with varied categories of SOFA scores, after adjustment of all independent predictors of 30-day mortality. 


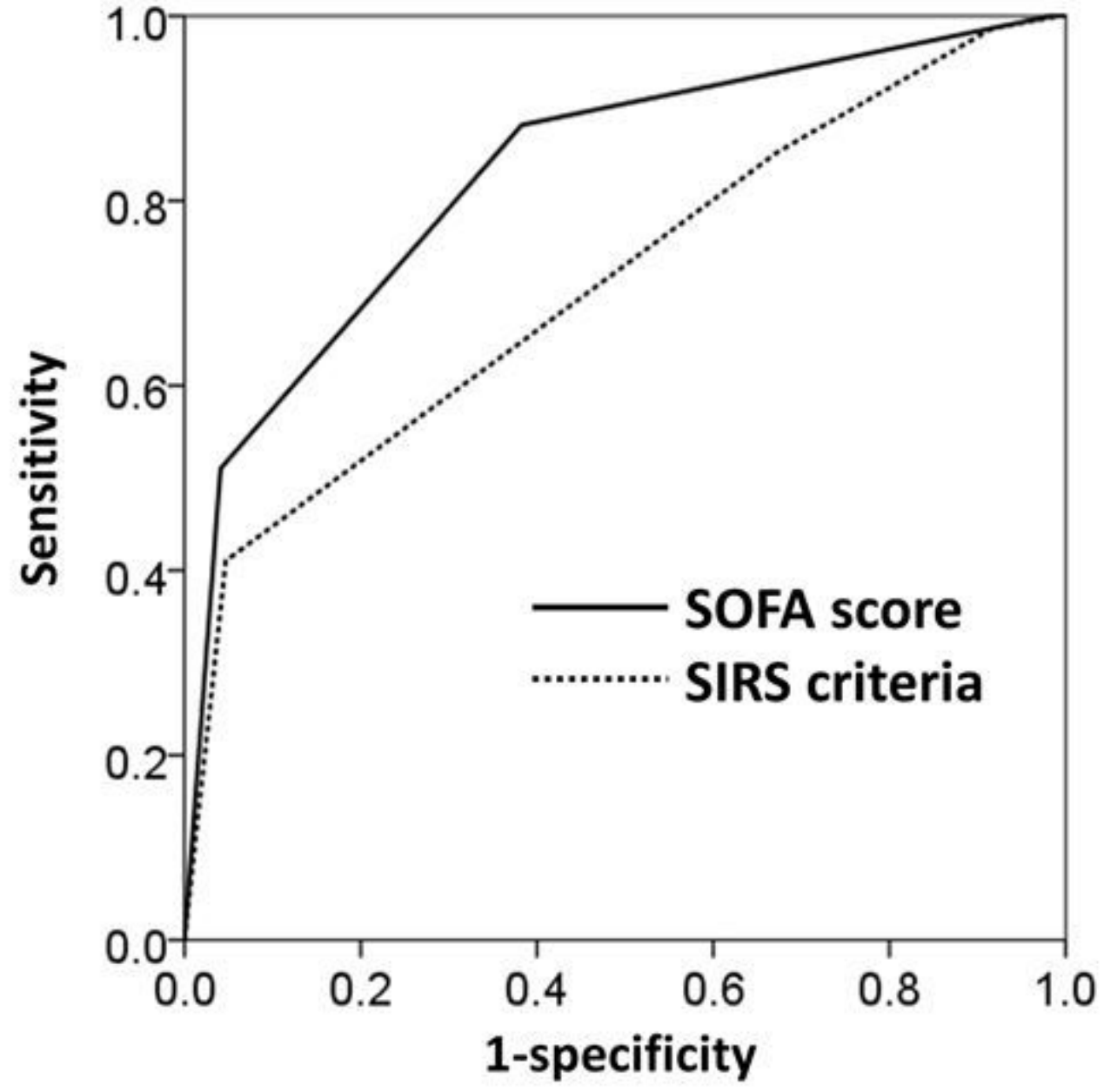

Figure 5

Receiver operating characteristic (ROC) curves of the SOFA and SIRS scores to predict 30-day crude mortality among patients with community-onset bacteremia. 